\title{
Retraction Note: Further notice of formal retraction of articles by Dr. Yoshitaka Fujii
}

\section{Retraction to: J Anesth (1997) 11:126-129 DOI 10.1007/BF02480074, J Anesth (1996) 10:22-25 DOI 10.1007/BF02482063, J Anesth (1996) 10:176-180 DOI 10.1007/BF02471386, J Anesth (1995) 9:58-60 DOI 10.1007/BF02482037, J Anesth (1995) 9:343-347 DOI 10.1007/BF02479949, J Anesth (1994) 8:301-304 DOI 10.1007/BF02514655}

To readers of the Journal of Anesthesia:

In addition to the articles listed in a retraction note in $J$ Anesth (2013) 27:322, the following articles published by Dr. Yoshitaka Fujii in the Journal of Anesthesia also are hereby retracted as a result of: (1) overwhelming evidence of fabrication related to the fact that the distributions of many variables reported by Dr. Fujii in these studies are exceedingly unlikely [1] and (2) the inability of Dr. Fujii's institution to attest to the integrity of the study and/or the data conducted under its auspices, as set out in the Joint Editors-in-Chief Request for Determination of April 9, 2012 [2].

*Fujii Y, Udagawa T, Toyooka H. Effects of dobutamine on the fatigued diaphragm: a comparison with dopamine. J Anesth. 1994;8:301-4.

The online version of the original article can be found under doi:10.1007/BF02480074, 10.1007/BF02482063, 10.1007/BF02471386, 10.1007/BF02482037, 10.1007/BF02479949, 10.1007/BF02514655.
*Fujii Y, Toyooka H. The dose-response relationship of amrinone in increasing the contractility of fatigued diaphragm in dogs. J Anesth. 1995;9:343-7.

*Fujii Y, Toyooka H. Effects of nicardipine on diaphragmatic fatigue in the dog: the relationship between dosage and fatigability. JA. 1995;9:58-60.

*Fujii Y, Toyooka H, Amaha K. Dibutyryl cyclic AMP increases the contractility of fatigued diaphragm in dogs. J Anesth. 1996;10:176-80.

*Fujii Y, Toyooka H. Dobutamine increases contractility of fatigued diaphragm in dogs: the relationship between dose and diaphragmatic contractility. J Anesth. 1996;10: 22-5.

*Fujii Y, Toyooka H. Nicardipine inhibits amrinoneenhanced contractility in fatigued diaphragm. J Anesth. 1997;11:126-9.

Kazuyoshi Hirota, MD PhD FRCA Editor-in-Chief, Journal of Anesthesia

\section{References}

1. Carlisle JB. The analysis of 168 randomised controlled trials to test data integrity. Anaesthesia. 2012;67:521-37.

2. Joint Editors-in-Chief letter. Available at: http://www.aaeditor. org/Fujii_Joint_EIC_Stmt.pdf. 